\title{
Effect of pressure and polishing technique on surface roughness of cold cured acrylic resin
}

\author{
Sianiwati Goenharto \\ Orthodontic Department \\ Faculty of Dentistry Airlangga University \\ Surabaya - Indonesia
}

\begin{abstract}
The smoothness of acrylic surface plays an important role in producing removable orthodontic appliances. Int this study, we examine the effect of pressure and polishing technique on surface roughness of cold cured acrylic resin. Forty eight samples were prepared and classified into two groups: acrylic resin polymerization with and without pressure. Each group was classified into four subgroups: being polished with abrasive stone, bur for acrylic, silicone polisher and without being polished as control group. Surface roughness was measured using surface roughness tester. The surface roughness of polymerized acrylic with and without pressure and polished with different technique was analyzed using One-Way ANOVA, continued by Dunnet test. T-test was done to know whether there was the effect of pressure on surface roughness after being polished using certain technique. The result showed that pressure and polishing technique affected surface roughness significantly $(p=0.001)$. On the group of polymerization with pressure, surface roughness resulted from polishing with bur of acrylic showed significant difference with silicone polisher, whereas on the group without pressure, polishing with bur of acrylic showed significant difference with abrasive stone. Of the three polishing techniques, there was significant difference of surface roughness of cold cured acrylic resin $(t=0.002)$. It is concluded that pressure and polishing technique affected the surface roughness of cold cured acrylic resin. Polishing technique using bur of acrylic, followed by abrasive paper, rotating felt cone and soft brush showed less surface roughness on the group of polymerization with or without pressure.
\end{abstract}

Key words: polymerization, pressure and polishing technique, cold cured acrylic

Correspondence: Sianiwati Goenharto, c/o: Bagian Ortodonsia, Fakultas Kedokteran Gigi Universitas Airlangga. Jln. Mayjend. Prof. Dr. Moestopo 47 Surabaya 60132, Indonesia.

\section{INTRODUCTION}

The smoothness of acrylic resin surface in removable orthodontic appliances is an important thing. A smooth exposed surface that is highly is good in aesthetic, give comfort, make oral health better, and the risk of plaque and debris attachment is smaller.

Nowadays, the role of heat cured acrylic in the process of making removable orthodontic appliance has been replaced by cold cured acrylic, ${ }^{1}$ including which polymerized with visible light cured. ${ }^{2}$ The base plate produced by heat cured acrylic is more solid, harder, no porosity with more stable color. However, the process is more complicated because wax model should be made and the acrylic processing will take long time. The instrument and the material which are needed are quite a lot, because, wax model should be flasked before polymerization process which need heat and pressure. ${ }^{1}$

The use of cold cured acrylic material will give advantage because it is cheaper, the working method is easier, time saving and the dimensional changing is small. 3,4 The particle size of cold cured acrylic powder is smaller than heat cured, so it is easier to be absorbed by monomer liquid. ${ }^{5}$ Changing the design of removable orthodontic appliance or reparation process can be done easier with this material. The main disadvantage of this material is the porosity is high so the debris will be easily attached and difficult to clean. Giving the pressure during polymerization process will enable to reduce acrylic porosity. The pressure over 4 atmosphere will not give any affect while 2-3 atmosphere will give positive effect. ${ }^{6}$

To achieve smooth surface, acrylic resin needs to perform polishing stage. There are various kinds of acrylic polishing techniques. The previous study showed that the use of abrasive stone followed consecutively by coarse abrasive disc, medium abrasive disc, fine abrasive disc, rotating felt cone with pumice slurry, rotating soft brush with chalk powder, will give the best polishing out come. $^{7}$

At the Diploma III Laboratory of Dental Health Technique Program of Faculty of Dentistry Airlangga University, bur of acrylic is usually used to polish acrylic, followed by abrasive paper, rotating felt cone with pumice slurry and also, rotating soft brush with chalk powder. Silicone polisher which can be used to smoothen the acrylic is available on the market. The use of silicone polisher is more practical and more advantageous because it will not defect the wire or the alloy which is possible on the base palate. The purpose of this study is to examine the effect of pressure and polishing technique toward surface roughness of cold cured acrylic resin, so it will be useful to increase the quality of removable orthodontic appliances. 


\section{MATERIAL AND METHOD}

This study was experimental laboratory with factorial design. To make the sample, brass plate master model, $60 \times 10 \times 2 \mathrm{~mm}$ in size was prepared, then hard gypsum mold was made according to the master model. Acrylic plate was made in gypsum mold using layering technique by spreading a layer of cold cured acrylic power (Vertex, Dentaurum) and followed by adding monomer liquid until the whole monomer infiltrate into the polymer powder. The process was repeated until the required form according to the criteria was achieved.

Forty eight samples were prepared and classified into two groups i.e. acrylic polymerization groups with and without pressure. Immediately after acrylic processing was completed, samples of the first group were put into polyclav containing water in $50^{\circ} \mathrm{C}$ and the pressure given was 2,2 atmosphere for 10 minutes. The second group samples were done without pressure (without polyclav). Polymerization groups with (group 1) or without (group 2) pressure was classified into four subgroups, consisted of six specimens in which would be polished in different technique. Technique I (subgroup) using rough abrasive stone for 40 seconds, followed by fine abrasive stone for 20 seconds, rotating felt cone with pumice slurry for 45 seconds, and polished by soft brush with chalk powder for 15 seconds. Technique II (subgroup 2) using bur of acrylic for 30 seconds, followed by abrasive paper no 0 for 15 seconds, rotating felt cone with pumice slurry for 45 seconds, and polished by soft brush with chalk powder for 15 seconds. Technique III (subgroup 3) using rough silicone polisher for 60 seconds, continued by smooth silicone polisher for 30 seconds, rotating felt cone with pumice slurry for 45 seconds, and polished by soft brush with chalk powder for 15 seconds. Subgroup 4 was not polished (as control group). The acrylic plate should be cleansed with running water when the instrument changed.

Surface roughness of the acrylic resins was examined by surface roughness tester. The specimen was placed on the table so that the stylus of the instrument could freely move on specimen surface. The measurement distance was
$5 \mathrm{~mm}$ and the instrument moved in $0,75 \mathrm{~m} /$ second. Surface roughness was counted using pertograph i.e arithmetic mean of five differences peak to valley height. Rz showed the height and the depth of surface roughness in micron.

The data of acrylic resin surface roughness which polymerized with and without pressure and polished by different technique was tabulated and analyzed using One-Way ANOVA continued by Dunnett test with 0,05 significant grade. T-test was performed in order to know whether there was the effect of pressure on the surface roughness after being polished using certain technique.

\section{RESULT}

The data of average surface roughness $(\mathrm{Rz})$ of cold cured acrylic resin which was polymerized with and without pressure and polished by using different technique can be seen on table 1 .

Table 1 shows that the value of $\mathrm{Rz}$ in group without pressure with all technique relatively higher than the group with pressure. Before one-way ANOVA test was done, Kolmogorov-smironov test showed $\mathrm{p}>0.05$ which means the data of the whole samples groups had normal distribution. The value of homogeneity variant test: $p=0.028(p<0.05)$ means the data was homogeneous. In order to know whether there is the effect of polishing technique in surface roughness of cold cured acrylic which polymerized with pressure, One-Way ANOVA test was done and $p=0.001(p<0.05)$ was found, means there was significant difference on surface roughness of cold cured acrylic resins which polished in different technique. In order to know whether there is significant difference of the three polishing techniques on the surface roughness, Dunnet test was done (Table 2).

Tabel 2 showed that all techniques resulting significant difference of surface roughness with controlled group, as well as between technique II and III.

To know whether there is the effect of polishing technique in surface roughness of polymerized acrylic without pressure, One-Way ANOVA was done and

Table 1. The mean and the standard deviation of surface roughness $(\mathrm{Rz})$ of cold cured acrylic resin on various groups

\begin{tabular}{lccc}
\hline \multicolumn{1}{c}{ Group/subgroup } & $\begin{array}{c}\text { Number } \\
\text { of samples }\end{array}$ & $\begin{array}{c}\text { Mean } \\
\text { Rz }(\mu \mathrm{m})\end{array}$ & $\begin{array}{c}\text { Standard } \\
\text { deviation }\end{array}$ \\
\hline Polymerization with pressure, polishing technique I & 6 & 2.47 & 0.46 \\
Polymerization with pressure, polishing technique II & 6 & 2.02 & 0.17 \\
Polymerization with pressure, polishing technique III & 6 & 2.98 & 0.49 \\
Polymerization with pressure, without polishing & 6 & 43.60 & 15.95 \\
Polymerization without pressure, polishing technique I & 6 & 6.97 & 1.59 \\
Polymerization without pressure, polishing technique II & 6 & 2.45 & 1.00 \\
Polymerization without pressure, polishing technique III & 6 & 10.02 & 6.51 \\
Polymerization without pressure, without polishing & 6 & 67.33 & 17.57 \\
\hline
\end{tabular}


Table 2. Significant difference of surface roughness $(\mathrm{Rz})$ among the groups of different polishing technique in polymerization with pressure using Dunnet test.

\begin{tabular}{lcccc}
\hline \multicolumn{1}{c}{ Subgroup } & Technique I & Technique II & Technique III & Control \\
\hline Technique I & - & 0.277 & 0.385 & $0.007^{*}$ \\
Technique II & & - & $0.019 *$ & $0.007^{*}$ \\
Technique III & & - & $0.007^{*}$ \\
Control & & & & - \\
\hline
\end{tabular}

Note: $*$ significant difference $(\mathrm{p}<0.05)$

Table 3. The significant difference of the surface roughness $(\mathrm{Rz})$ between groups with different polishing technique in polymerization without pressure using Dunnet test

\begin{tabular}{lcccc}
\hline \multicolumn{1}{c}{ Subgroup } & Technique I & Technique II & Technique II & Control \\
\hline Technique I & - & $0.002 *$ & 0.826 & $0.002^{*}$ \\
Technique II & & - & 0.157 & $0.001 *$ \\
Technique III & & - & $0.001 *$ \\
Control & & & & - \\
\hline
\end{tabular}

Notes: $*=$ significant difference $(\mathrm{p}<0.05)$

$\mathrm{p}=0.001(\mathrm{p}<0.005)$ was found, means polishing technique affect the surface roughness of polymerized acrylic without pressure. On homogeneity test, $\mathrm{p}=0.001(\mathrm{p}<0.005)$ was found so in order to know whether there is significant difference of the three polishing technique towards the surface roughness, Dunnet test was done (Table 3 ).

Table 3 showed that all techniques giving significant difference of surface roughness with controlled group as well as technique I and II. T-test was done in order to know whether there is difference of surface roughness of polymerized cold cured acrylic with and without pressure, and in the three technique $\mathrm{t}=0.002(\mathrm{t}<0.005)$ was found, which means there is effect of pressure in surface roughness of cold cured acrylic after being polished with a certain technique. $t$ value in controlled group was 0.537 $(t>0.05)$ means that there was no difference of surface roughness of polymerized cold cured acrylic with and without pressure.

\section{DISCUSSION}

The smoothness surface of acrylic resin on orthodontic treatment with removable appliance is considerably important factor to support the success of treatment. A rough surface may be uncomfortable and food debris and plaque can adhere easily to it. ${ }^{8}$ Polishing is done to inhibit adhesion, to make the surface feel smooth and to increase aesthetic. ${ }^{9}$ Resin which is smoothly polished and shiny, will be more comfortable for the patient, debris will not be easily attached, and also it will reduce the risk of decreasing hygiene and oral health, in addition, the possibility of having bad smell after being worn for some times will be prevented.

This study showed that polishing technique will affect the surface roughness of cold cured acrylic resin which was polymerized with pressure $(\mathrm{p}=0.02)$. Dunnet test shows (Table 2) that polishing with the three techniques can result significant surface roughness which was lower than unpolished group. The result can be understood because the purpose of polishing is to achieve smoother surface. The three techniques which are applied in this study are based on polishing principle i.e by using rougher to smoother instrument with acrylic resin cleansing in running water every time prior to instrument change, ${ }^{8}$ because particle material that left on the surface can be scratched during polishing period. ${ }^{10}$ Grinding and polishing phases should be done step by step without neglecting any step.

Polishing technique with silicone polisher (technique III), had significantly higher surface roughness compared with bur for acrylic (technique II). In this case, it is due to sharpness factor and the hardness of instrument. Bur for acrylic is sharper and harder compared with silicone polisher that made from such a rubber, and also abrasive paper is sharper than fine silicone polisher. Sharp instrument is more capable to cut and eliminate the rough part. Silicone polisher is more blunt but advantageous because it does not defect either the wire or the alloy on the design of removable orthodontic appliance. Careless use of sharp instrument can contribute defect on the other component of removable orthodontic appliances.

This study also showed that polishing technique might affect the average roughness of cold cured acrylic resin with which is polymerized without pressure $(\mathrm{p}=0.001)$. 
Dunnet test (Table 3) showed that polishing with the three techniques resulting significantly lower surface roughness than in the unpolished group.

In polymerization group without pressure, polishing technique with abrasive stone (technique I) gave significant higher surface roughness compared with bur for acrylic (technique II). In this case, it is possible due to the characteristic of bur of acrylic made of metal (tungsten carbide) relatively harder compared with abrasive stone made of silicone carbide. The harder material will be more capable to dispose the rough part. This result differs from polymerization group with pressure. This is possibly because the porosity which affect the smoothness of acrylic resin surface. Giving the pressure during the polymerization process of cold cured acrylic can decrease the amount of porosity. Porosity is caused by the residual monomer. Polymerization of cold cured acrylic resin is never as complete as heat cured acrylic resin. In this case, it will result more residual monomer on cold cured acrylic resin i.e. 3-5\% compared with the amount of residual monomer on heat cure i.e. only $0,2-0,5 \% .{ }^{11}$ One of the techniques to reduce the amount of residual monomer recommended is auto polymerization process in the water with pressure. The process of cold cured acrylic polymerization in a pressure pot might result stronger acrylic with less porosity and shrinkage. The use of polyclav also make acrylic resin immersed in water. The water immersion might also be able to reduce residual monomer due to the occurrence of releasing residual monomer. ${ }^{13}$ Polishing can also dispose the excessive material, smoothen the rough surface, ${ }^{9}$ and also decrease the amount of residual monomer. ${ }^{14}$ Therefore, on polymerization process with pressure, due to the less amount of porosity, there was no significant different of surface roughness resulted from polishing technique I and II.

Although abrasive stone and bur of acrylic are sharper than silicone polisher but there was no significant different on surface roughness of polymerization group without pressure. This is possibly caused by the solidity of acrylic that polymerized without pressure is lower than polymerization with pressure, so even though silicone polisher is more blunt but capable to dispose the rough part similar with the other two techniques. In addition the value of standard deviation on polishing group with silicone polisher was high. In this study, it was difficult to obtain polishing with true uniformity. In fact the speed of movement and pressure performed during polishing might influence the polishing result. $^{3}$

This study also showed that the three techniques of polishing, pressure will affect the surface roughness of cold cured acrylic resin $(\mathrm{t}=0,002)$. On unpolished group, significant difference was not found. Polishing is very important because without it, a rough acrylic will be produced either in the group of polymerization with or without pressure. So, polishing factor plays more important role in surface roughness decreasing than pressure factor.

It is concluded that pressure and polishing technique affected the surface roughness of cold cured acrylic resin. Polishing technique using bur of acrylic, followed by abrasive paper, rotating felt cone and soft brush showed less surface roughness on the group of polymerization with or without pressure.

\section{ACKNOWLEDGEMENT}

The author would like to thank to Lembaga Penelitian Universitas Airlangga which had given the sponsorship to do this study.

\section{REFFERENCES}

1. Adams CP. The design and construction of removable orthodontic appliances. $4^{\text {th }}$ ed. Bristol: John Wright \& Sons Ltd; 1990. p. $186-8$.

2. Brown K. Light-curing acrylic resin as an orthodontic baseplate materials. Quint Int 1998; 29:508-12.

3. Combe EC. Notes on dental materials. $7^{\text {th }}$ ed. Edinburg, London, Melbourne, New York: Churchill Livingstone; 1992. p. 258-60, 332-4.

4. Isaacson KG, Muir JD, Reed RT. Removable orthodontic appliances. Oxford, Auckland, Boston: Wright; 2002. p. 35.

5. Van Noort R. Introduction to dental materials. $2^{\text {nd }}$ ed. Edinburg: Mosby; 2002. p. 228-9.

6. Furnish GM, O'Toole TJ, Fraunhofer JA. The polymerization of acrylic resin orthodontics. J Prost Dent 1983; 49:276-8.

7. Ulusoy M, Ulusoy N, Aydin AK. An evaluation of polishing techniques on surface roughness of acrylic resins. J Prost Dent 1986; 56:107-12.

8. Craig RG, Powers JM, Wataha JC. Dental materials: properties and manipulation. $8^{\text {th }}$ ed. St. Louis: Mosby; 2004. p. 110-2, 270-89.

9. Gladwin M, Bagby M. Clinical aspect of dental materials: theory, practice and cases. $2^{\text {nd }}$ ed. Philadelphia, Baltimore: Lippincott Williams \& Wilkins; 2004. p. 153, 205-8.

10. Craig RG. Restorative dental materials. $10^{\text {th }}$ ed. St. Louis, Baltimore, Boston: Mosby; 2002. p. 521.

11. Anusavice KJ. Phillip's science of dental materials. $11^{\text {th }}$ ed. Philadelphia: WB Saunders Co; 2003. p. 663-79.

12. Hatrick CD, Eakle WS, Bird WF. Dental materials: clinical applications for dental assistants and dental hygienists. Philadelphia, London, New York: Saunders; 2003. p. 263.

13. Retno A, Intan N, Anita Y. Jumlah pelepasan monomer sisa resin akrilik jenis heat cured dalam air. Maj Ked Gigi (Dent J) 2005; Ed khusus: 43-6.

14. Kejarune U. Release of methyl methacrylate from heat cured and autopolymerized resin; cytotoxicity testing related to residual monomer. Australian Dent J 1999; 44(1):25-30. 